\title{
Current Trends in
}

\section{Entomology and Zoological Studies}

\section{Temperature Dependent Development of Sugarcane Aphids Melana- phis Sacchari, (Hemiptera: Aphididae) on Three Different Host Plants with Estimates of the Lower and Upper Threshold for Fecundity}

\author{
Misael A De Souza ${ }^{1}$, J Scott Armstrong ${ }^{2 *}$, W Wyatt Hoback ${ }^{1}$, Phillip G Mulder ${ }^{1}$, Sulochana Paudyal ${ }^{1}$, John E Foster ${ }^{3}$, Mark E \\ Payton $^{4}$, Josephine Akosa ${ }^{5}$
}

${ }^{1}$ Department of Entomology and Plant Pathology, Oklahoma State University, USA

${ }^{2}$ United States Department of Agriculture Agricultural Research Service, Wheat, Peanut, and Other Field Crops Research Unit, USA

${ }^{3}$ Department of Entomology, University of Nebraska-Lincoln, USA

${ }^{4}$ Department of Statistics, Oklahoma State University, USA

${ }^{5}$ Department of Information Technology, University of Notre Dame, USA

"Corresponding author: J Scott Armstrong, United States Department of Agriculture Agricultural Research Service, Wheat, Peanut, and Other Field Crops Research Unit, USA. Tel: 4056244141 Ext: 222; E-mail: scott.armstrong@ars.usda.gov

Citation: Souza MA, Armstrong JS, Hoback WW, Mulder PG, Paudyal S, et al. (2019) Temperature Dependent Development of Sugarcane Aphids Melanaphis Sacchari, (Hemiptera: Aphididae) on Three Different Host Plants with Estimates of the Lower and Upper Threshold for Fecundity. Curr Trends Entomol Zool Stds 2: 1011. DOI:10.29011/CTEZS-1011.001011

Received Date: 23 October, 2019; Accepted Date: 13 November, 2019; Published Date: 19 November, 2019

\begin{abstract}
The sugarcane aphid, Melanaphis sacchari (Zehntner) is a serious economic threat to grain sorghum across the U.S. sorghum belt. It can develop on multiple grass hosts but only appears to survive winter temperatures in Texas near the Mexican border, Florida and Louisiana. Because survival and reproduction of aphids is dependent on access to appropriate nutrition and temperatures at which metabolic processes are maintained, we evaluated the growth, reproduction and survival of sugarcane aphids at constant temperatures $\left(5^{\circ} \mathrm{C}, 10^{\circ} \mathrm{C}, 15^{\circ} \mathrm{C}, 20^{\circ} \mathrm{C}, 25^{\circ} \mathrm{C}, 30^{\circ} \mathrm{C}, 35^{\circ} \mathrm{C}\right)$ on three known hosts, sorghum, Johnsongrass, and Columbus grass. Longevity, fecundity, number of female nymphs/d, reproductive period in $\mathrm{d}$, and intrinsic rate of increase were measured at $24 \mathrm{~h}$ intervals. At temperatures below $10^{\circ} \mathrm{C}$ and above $30^{\circ} \mathrm{C}$, reproduction did not occur on any of the hosts. Longevity was maximal at $15^{\circ} \mathrm{C}$ and thereafter decreased with increasing temperatures. The intrinsic rate of increase was highest between $15^{\circ} \mathrm{C}$ and $25^{\circ} \mathrm{C}$ on all host plants, while maximum fecundity differed by host plant and was greatest on sorghum. For aphids feeding on sorghum, the Weibull and Natural models were used to estimate lower and upper thresholds for development based on daily fecundity. The lower threshold for fecundity was $9^{\circ} \mathrm{C}$, while the upper threshold for fecundity was $32^{\circ} \mathrm{C}$. These results suggest that sugarcane aphid can use alternate hosts for survival and reproduction, but both low and high temperatures limit its reproductive capacity. Higher temperatures may trigger dispersal, while lower temperatures should limit sugarcane aphid fecundity and survival in most of the US.
\end{abstract}

Keywords: Growth; Host Plants; Reproduction; Sugarcane Aphid; Temperature Threshold

The sugarcane aphid, Melanaphis sacchari (Zehntner) is a pest of sorghum, Sorghum bicolor (L.) Moench, in many parts of the world. In 2013 it became epidemic on sorghum in the United
States [1,2]. Although the species was first introduced to the U.S. in the 1970s from Hawaii it was only known to be a pest of sugarcane. Reported hosts of the sugarcane aphid include sugarcane Saccarum officinarum L., Johnsongrass Sorghum halepense (L) Pers., and Columbus grass Sorghum almum Parodi especially in the southern US $[3,4]$. The reproduction and longevity of the 


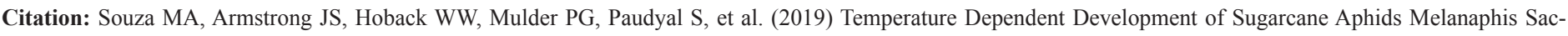

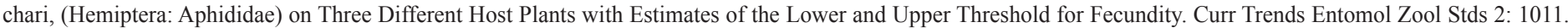
DOI:10.29011/CTEZS-1011.001011

sugarcane aphid has also been tested on bioenergy grasses such as energycane (Saccharum spp.), giant miscanthus (Miscanthus x giganteus or Miscanthus sinensis x M. sacchariflorus Greef \& Deuter ex Hodkinson \& Renvoize) and found to be good hosts that supported reproduction, while poor hosts included the napiergrass [Cenchrus purpureus (Schumach.) Morrone] cultivar Merkeron, giant reed (Arundo donax L.), and switchgrass (Panicum virgatum L.) cultivar GA-001 [5]. The clonal lineage of the sugarcane aphid that damages sorghum in the US has been identified as MLL-F and was introduced to North America in 2013 from either Africa or Asia [2].

Observations made from the recent epidemic in the US [6] and from previously published literature from countries such as South Africa [7], and India [8], reports that sugarcane aphid prefers to infest sorghum on the underside of the lower leaves where reproducing colonies increase rapidly from flowering to grain-fill. The entire plant, including the inflorescence and leaves, can be covered in honey dew and sooty mold. Heavy infestations of the sugarcane aphid produce sticky biomass that can cause mechanical problems with harvesting equipment, reducing the yield efficiency, and increasing equipment costs [9].

Temperature is the most important abiotic factor affecting the development and reproduction of aphids $[10,11]$. When aphids are exposed to temperatures below the threshold for development, survival is possible, but growth and maturation cease [12]. As temperatures increase above the lower threshold of development, development rates increase in an almost linear manner to some thermal optimum, beyond which development slows as a consequence of physiological stress. However, when temperatures become too high, the rate of development decreases as a result of physiological stress. These temperature limits, also known as lower and upper development thresholds are often speciesspecific [12]. Our research objectives were to determine the effects of temperature on sugarcane aphid survival, development, and fecundity on three known host plants. From these results we estimated the lower and upper temperature thresholds for lifetime fecundity on sorghum using two different statistical models across the temperature ranges.

\section{Materials and Methods}

\section{Aphid Origin and Culture}

Sugarcane aphids used in this experiment originated from a collection of grain sorghum in Matagorda county, Texas in August of 2013. A single parthenogenic female from this collection was transferred to a single sorghum plant RTx7000 that is known to be susceptible to sugarcane aphids [3]. From this founding female, thirteen additional colonies were started by placing a single nymph from the original female on single plants. The colonies were maintained by transferring them to new seedling plants every 2 weeks in a greenhouse maintained at temperatures ranging from $21{ }^{\circ} \mathrm{C}$ to $31{ }^{\circ} \mathrm{C}$. The colonies used in this study were determined to be the MLL-F clonal lineage as described by Nibouche, et al. [2].

\section{Effects of Temperature on Life History}

To evaluate survival and reproduction of sugarcane aphids at different temperatures, a susceptible sorghum cv KS 585 and two non-cultivated hosts, Johnsongrass and Columbus grass were utilized as host plants. Johnsongrass seeds were obtained from the Oklahoma State University, Cimarron Valley Experiment Station located in Perkins, OK. Columbus grass seeds were purchased from Turner Seed Company (Breckenridge, Texas). Sorghum was grown by planting two seeds within a cone-tainer (model SC10, S7S greenhouse supply, Tangent, Oregon) measuring $5 \mathrm{~cm}$ in diameter x $20 \mathrm{~cm}$ tall with a three-layer media of potting soil, fritted clay and sand (from bottom to top respectively). When the seedlings reached the three-leaf stage, the most vigorous were left in the containers while the other was removed. A clear plastic cylinder tube (Round Tube-4 feet MW-1 3/8" PETG-Clear-StockPolybag) with three holes covered with polyester fine mesh netting for ventilation was used to protect the plants.

The seeds of Johnsongrass and Columbus grass required different environmental conditions for germination. Both types of seed were scarified to remove the outer shell followed by placing the seeds between moist paper towels within a Ziploc $\AA$ bag. The bag was placed in an environmental growth chamber (Percival ${ }^{\circledR}$ Model E30B, Perry, IA) at a temperature of $27^{\circ} \mathrm{C}$ and a cycle of 12/10 (L:D). After three d, the germinated seeds were transferred to a pot with potting soil where they remained for another five $d$ to allow for radical and root growth. After five d, a vigorous seedling was transplanted into a cone-tainer identical to the KS 585 grain sorghum.

When the plants reached the three-leaf stage, 10 replicates of cone-tainers for each of the three species of plants were placed in a cone-tainer rack. Using a camel hair brush, one sugarcane aphid nymph was placed on one leaf of each plant. Each rack was then placed in a growth chamber, previously set at constant temperatures of $5^{\circ} \mathrm{C}, 10^{\circ} \mathrm{C}, 15^{\circ} \mathrm{C}, 20^{\circ} \mathrm{C}, 25^{\circ} \mathrm{C}, 30^{\circ} \mathrm{C}$ or $35^{\circ} \mathrm{C}$, with a photoperiod of $14: 10$ (L: D) hours and humidity of $65 \%$. From the time the single nymph turned to adult and started producing offspring, life parameters such as female longevity (d), Fecundity (total number of nymphs produced per female), number of nymphs produced per female/d, intrinsic rate of increase ( $\mathrm{rm})$, and reproductive period $\mathrm{Rp}$ (days actually producing nymphs) were recorded. Intrinsic rate of increase utilizes the $[(\mathrm{rm}=0.738(\log \mathrm{Md} / \mathrm{d})]$ formula where $\mathrm{d}$ is the pre-reproductive period of F1 in days, and 0.738 is the slope of Md over "d" days [13]. Every 24 h, each plant was observed for reproduction. Nymphs were counted and removed from the plant, 


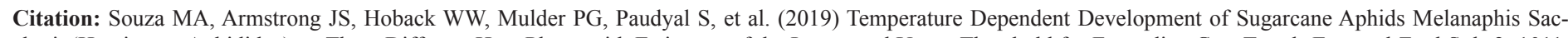

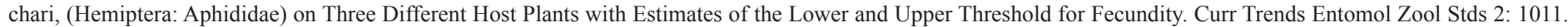
DOI:10.29011/CTEZS-1011.001011

leaving only the original female. Data were collected every $24 \mathrm{~h}$ until the original founding female died.

\section{Statistical Analysis}

All test variables including aphid longevity in $\mathrm{d}, 24 \mathrm{~h}$ fecundity, pre-reproductive and reproductive periods in $\mathrm{d}$ were analyzed using Mixed model analyses [14]; replications were considered as random effects. Mean comparisons for sugarcane aphid life parameters were carried out using the Difference in LS Means statement and adjusted by the Tukey-Kramer multiple comparisons test.

\section{Estimating Temperature Thresholds for Lifetime Fecundity}

A recent approach for determining the fecundity vs temperature threshold was demonstrated by Merrill, et al. [15], where both the Gaussian (also known as the Normal function) and the Weibull model [14], were used to estimate the fecundity thresholds for several different cereal aphids. We employed these models based on the strength of the AIC values as reported by Burnham and Anderson [16], and the fact that the distribution of fecundity takes on a multi-model or quadratic effect at more extreme temperatures $\left(5-10^{\circ} \mathrm{C}\right.$, and $\left.30-35^{\circ} \mathrm{C}\right)$. The thresholds were estimated using the Weibull probability distribution function and the Normal (Gaussian) function only on sorghum because it was the optimal host based on fecundity across the temperature ranges. In order to fit the model, optimization techniques were utilized to estimate the parameter values.

Consider the Weibull probability distribution function:

$$
y=f(x)=\frac{k}{\lambda}\left(\frac{x}{\lambda}\right)^{k-1} \exp \left\{-\frac{x^{k}}{\lambda}\right\} ; \quad x \geq 0,
$$

Where $k>0$ is the shape parameter and $\lambda>0$ is the scale parameter. SAS statistical language (MODEL procedure) was utilized to estimate the model parameters based on the given data. However, utilizing the original form of the function resulting in convergence issues. In order to overcome this, a model reparameterization was considered. Let $y^{*}=y+\gamma$ such that $y^{*}>0$ for

$\gamma>0$. Then we have

$$
y^{*}=c f(x)
$$

Where $f(x)=$ WEIBULL $(x ; k, \lambda)$ and $\mathrm{c}$ is a scaling constant for $\mathrm{y}$. Then,

$$
y^{*}=c\left[\frac{k}{\lambda}\left(\frac{x}{\lambda}\right)^{k-1} \exp \left\{-\left(\frac{x}{\lambda}\right)^{k}\right\}\right]
$$

Now, taking $\log$ on both sides of 3 , we obtain

$$
\begin{aligned}
& \log y^{*}=\log \left\{c\left[\frac{k}{\lambda}\left(\frac{x}{\lambda}\right)^{k-1} \exp \left\{-\left(\frac{x}{\lambda}\right)^{k}\right\}\right]\right\} \\
& y=a+(k-1) \log \frac{x}{\lambda}-\left(\frac{x}{\lambda}\right)^{k},
\end{aligned}
$$

Where, $y^{*}=\log y^{*}$ and $\mathrm{a}=\log \left(\frac{c k}{\lambda}\right)$. Then, given $\hat{a}, \hat{k}$ and $\hat{\lambda}$, we have

$$
\hat{y}=-\gamma+\exp \left\{\hat{a}+(\hat{k}-1) \log \left(\frac{x}{\hat{\lambda}}\right)-\left(\frac{x}{\hat{\lambda}}\right)^{k}\right\}
$$

In order to solve for the parameter estimates, the PROC MODEL function in SAS was utilized with equation (5) and a back transformation was performed to obtain the original parameter estimates.

Consider the probability distribution function of the normal model:

$$
y=f(x)=\frac{1}{\sqrt{(2 \pi)} \sigma} \exp \left\{-\frac{1}{2}\left(\frac{x-\mu}{\sigma}\right)^{2}\right\}
$$




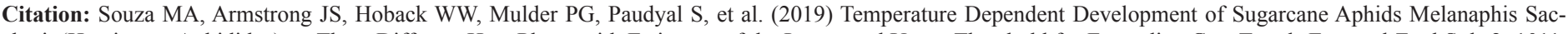

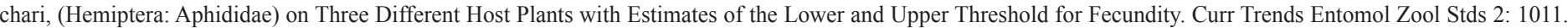
DOI:10.29011/CTEZS-1011.001011

Following the same arguments with the Weibull distribution, we reparametrize the normal model and end up with the model

$$
\hat{y}=-\gamma+\exp \left\{-\frac{1}{2} \log (2 \pi)+\hat{a}-\frac{1}{2}\left(\frac{x-\hat{\mu}}{\hat{\sigma}}\right)^{2}\right\}
$$

Where, $\hat{a}=\log \frac{\hat{c}}{\hat{\sigma}}$. Similarly, using the PROC MODEL function in SAS the parameter estimates were obtained.

\section{Results}

\section{Temperature and Life History}

Sorghum is the optimal host plant based on reproductive potential and longevity of the MLL-F clonal lineage of sugarcane aphid when reared at constant temperatures of $5{ }^{\circ} \mathrm{C}, 10^{\circ} \mathrm{C}, 15^{\circ} \mathrm{C}, 20^{\circ} \mathrm{C}, 25^{\circ} \mathrm{C}, 30{ }^{\circ} \mathrm{C}$ and $35^{\circ} \mathrm{C}$, followed by Johnsongrass and then Columbus grass (Tables 1-3). At the lowest $\left(5^{\circ} \mathrm{C}\right)$ and highest $\left(35^{\circ} \mathrm{C}\right)$ temperature, the founding sugarcane aphid females did not survive more than $9 \mathrm{~d}$, and no reproduction occurred on any host (Tables 1-3). On Columbus grass at $10^{\circ} \mathrm{C}$, the founding female survived for $14 \mathrm{~d}$, but no reproduction occurred making it impossible to measure fecundity,Rp,d,md, and rm (Table 3). Overall sugarcane aphid longevity was higher on sorghum than on Johnsongrass and Columbus grass. Longevity was the greatest at $15^{\circ} \mathrm{C}$, on sorghum and Johnsongrass at 47 and $44 \mathrm{~d}$ respectively. However, on Columbus grass, longevity was highest at $20^{\circ} \mathrm{C}$ and averaged $31 \mathrm{~d}\left(\right.$ Tables $1-3$ ). At $15{ }^{\circ} \mathrm{C}$, sugarcane aphid survival was greatest for sorghum and Johnsongrass, but on Columbus grass the longest survival occurred at $20^{\circ} \mathrm{C}$.

\begin{tabular}{|c|c|c|c|c|c|c|c|}
\hline Temperature $\left({ }^{\circ} \mathbf{C}\right)$ & Longevity (d) & Fecundity & Nymphs/day & Rp & d & md & rm \\
\hline 5 & $8.8 \pm 1.4 \mathrm{~d}$ & - & - & - & - & - \\
\hline 10 & $31.2 \pm 3.0 \mathrm{~b}$ & $3.7 \pm 2.7 \mathrm{c}$ & $0.1 \pm 0.1 \mathrm{c}$ & $5.0 \pm 4.0 \mathrm{~d}$ & $33.3 \pm 1.3 \mathrm{a}$ & $3.7 \pm 2.7 \mathrm{c}$ & - \\
\hline 15 & $47.4 \pm 4.6 \mathrm{a}$ & $58.1 \pm 7.2 \mathrm{a}$ & $1.2 \pm 0.1 \mathrm{~b}$ & $26.1 \pm 2.5 \mathrm{a}$ & $14.5 \pm 1.4 \mathrm{~b}$ & $34.8 \pm 6.9 \mathrm{a}$ & $0.15 \pm 0.0 \mathrm{~d}$ \\
\hline 20 & $30.5 \pm 1.9 \mathrm{~b}$ & $61.5 \pm 4.5 \mathrm{a}$ & $2.0 \pm 0.1 \mathrm{a}$ & $20.6 \pm 1.6 \mathrm{bc}$ & $7.3 \pm 0.4 \mathrm{c}$ & $29.8 \pm 3.9 \mathrm{a}$ & $0.33 \pm 0.0 \mathrm{c}$ \\
\hline 25 & $28.8 \pm 2.2 \mathrm{~b}$ & $67.3 \pm 4.8 \mathrm{a}$ & $2.4 \pm 0.2 \mathrm{a}$ & $18.8 \pm 2.5 \mathrm{c}$ & $6.0 \pm 0.3 \mathrm{~cd}$ & $27.3 \pm 4.2 \mathrm{a}$ & $0.40 \pm 0.2 \mathrm{a}$ \\
\hline 30 & $16.9 \pm 1.8 \mathrm{c}$ & $39.8 \pm 4.7 \mathrm{~b}$ & $2.4 \pm 0.4 \mathrm{a}$ & $10.8 \pm 1.6 \mathrm{~d}$ & $5.1 \pm 0.1 \mathrm{~d}$ & $23.5 \pm 1.6 \mathrm{~b}$ & $0.45 \pm 0.1 \mathrm{~b}$ \\
\hline 35 & $8.7 \pm 1.2 \mathrm{~d}$ & - & - & - & - & - & - \\
\hline
\end{tabular}

Means followed by the same letter are not significantly different, LS Means, adjusted by Tukey-Kramer.

Longevity $=\mathrm{df}=4,36 ; \mathrm{F}=15.39 ; \mathrm{P}>\mathrm{F}=0.0001$.

Fecundity $=\mathrm{df}=4,29.8, \mathrm{~F}=11.67 ; \mathrm{P}>\mathrm{F}=0.0001$.

Nymphs per day $=d f=4,38 ; F=28.5 ; P>F=0.0001$.

$\operatorname{Rp}($ Reproductive period $)=\mathrm{df} 4,38, \mathrm{~F}=10.13 \mathrm{P}>\mathrm{F}=0.0001$.

$\mathrm{d}($ Pre-reproductive period $)=\mathrm{df}=4,38 ; \mathrm{F}=103.38 \mathrm{P}>\mathrm{F}=0.0001$.

$\mathrm{md}$ (Number of progeny produced in a reproductive period equal to the pre-reproductive period) $=\mathrm{df}=4,38 ; \mathrm{F}=3.06 ; \mathrm{P}>\mathrm{F}=0.0278$.

$\mathrm{rm}($ Intrinsic rate of increase $)=\mathrm{df}=3,36 ; \mathrm{F}=62.71 ; \mathrm{P}>\mathrm{F}=0.0001$.

Table 1: Mean ( \pm 1 S.E.) longevity and number of offspring produced for sugarcane aphid at different temperatures $\left({ }^{0} \mathrm{C}\right)$ when reared on grain sorghum. 


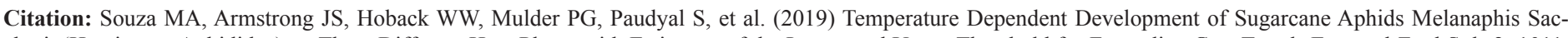

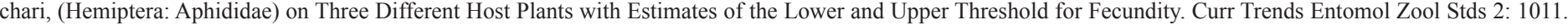
DOI:10.29011/CTEZS-1011.001011

\begin{tabular}{|c|c|c|c|c|c|c|c|}
\hline $\begin{array}{c}\text { Temperature } \\
\left({ }^{\circ} \mathrm{C}\right)\end{array}$ & Longevity (d) & Fecundity & Nymphs/day & $\mathbf{R p}$ & d & md & rm \\
\hline 5 & $3.9 \pm 1.1 \mathrm{f}$ & - & - & - & - & - & - \\
\hline 10 & $36.8 \pm 7.4 \mathrm{bc}$ & $8.2 \pm 2.5 \mathrm{c}$ & $0.14 \pm 0.1 \mathrm{~d}$ & $12.0 \pm 3.1 \mathrm{~b}$ & $39.4 \pm 1.4 \mathrm{a}$ & $8.2 \pm 2.5 b$ & $0.04 \pm 0.1 \mathrm{~d}$ \\
\hline 15 & $44.3 \pm 4.3 \mathrm{a}$ & $39.5 \pm 5.4 \mathrm{a}$ & $0.90 \pm 0.1 \mathrm{bc}$ & $24.7 \pm 3.3 \mathrm{a}$ & $14.9 \pm 0.7 b$ & $25.6 \pm 4.1 \mathrm{a}$ & $0.16 \pm 0.1 \mathrm{c}$ \\
\hline 20 & $31.6 \pm 4.2 \mathrm{c}$ & $40.5 \pm 9.6 \mathrm{a}$ & $1.2 \pm 0.3 \mathrm{~b}$ & $14.7 \pm 2.7 b$ & $11.7 \pm 0.8 \mathrm{c}$ & $21.9 \pm 4.4 \mathrm{a}$ & $0.20 \pm 0.3 \mathrm{c}$ \\
\hline 25 & $23.7 \pm 2.6 \mathrm{~d}$ & $48.3 \pm 7.1 \mathrm{a}$ & $2.2 \pm 0.4 \mathrm{a}$ & $15.0 \pm 2.1 \mathrm{~b}$ & $6.8 \pm 0.5 \mathrm{c}$ & $25.8 \pm 4.3 \mathrm{a}$ & $0.36 \pm 0.1 \mathrm{~b}$ \\
\hline 30 & $14.6 \pm 1.4 \mathrm{e}$ & $32.7 \pm 6.9 b$ & $2.0 \pm 0.4 \mathrm{a}$ & $7.4 \pm 0.9 b$ & $5.4 \pm 0.3 \mathrm{c}$ & $23.8 \pm 3.7 \mathrm{a}$ & $0.42 \pm 0.1 \mathrm{a}$ \\
\hline 35 & $4.2 \pm 1.2 \mathrm{f}$ & - & - & - & - & - & - \\
\hline
\end{tabular}

Means followed by the same letter are not significantly different; LS Means, adjusted by Tukey-Kramer.

Longevity: $\mathrm{df}=6,54 ; \mathrm{F}=17.81 P>F=0.0001$

Fecundity: $\mathrm{df}=4,30.4 ; \mathrm{F}=4.79 ; P>F=0.0041$

Nymphs/day: $\mathrm{df}=4,30.4 ; F=11.00 ; P>F=0.0001$.

Rp (Reproductive period): $\mathrm{df}=4,39.0 F=6.54 P>F=0.0004$

d (Pre-reproductive period): $\mathrm{df}=4,32.1 ; F=245.97 ; P>F=0.0001$.

md (Number of progeny produced in a reproductive period equal to the pre-reproductive period): $\mathrm{df}=4,30.3 ; F=2.93 ; \mathrm{P}>F=0.0371$.

rm (Intrinsic rate of increase): $\mathrm{df}=4,29.9 ; F=22.97 P>F=0.0001$.

Table 2: Mean ( \pm 1 S.E.) longevity and number of offspring produced for sugarcane aphid at different temperatures $\left({ }^{0} \mathrm{C}\right)$ when reared on Johnsongrass.

\begin{tabular}{|c|c|c|c|c|c|c|c|}
\hline Temperature $\left({ }^{\circ} \mathbf{C}\right)$ & Longevity (d) & Fecundity & Nymphs/day & Rp & d & md & rm \\
\hline 5 & $3.1 \pm 0.2 \mathrm{~d}$ & - & - & - & - & - \\
\hline 10 & $13.9 \pm 2.8 \mathrm{c}$ & - & - & - & - & - \\
\hline 15 & $27.0 \pm 3.8 \mathrm{a}$ & $8.5 \pm 4.2 \mathrm{~d}$ & $0.33 \pm 0.1 \mathrm{c}$ & $11.0 \pm 2.0 \mathrm{bc}$ & $21.3 \pm 1.0 \mathrm{a}$ & $12.1 \pm 5.5 \mathrm{c}$ & $0.07 \pm 0.1 \mathrm{c}$ \\
\hline 20 & $31.4 \pm 2.1 \mathrm{a}$ & $62.9 \pm 7.4 \mathrm{a}$ & $2.00 \pm 0.2 \mathrm{a}$ & $18.7 \pm 1.6 \mathrm{a}$ & $10.5 \pm 0.8 \mathrm{~b}$ & $34.3 \pm 4.6 \mathrm{a}$ & $0.25 \pm 0.4 \mathrm{a}$ \\
\hline 25 & $20.2 \pm 2.4 \mathrm{~b}$ & $36.1 \pm 10.4 \mathrm{~b}$ & $1.74 \pm 0.5 \mathrm{a}$ & $12.2 \pm 1.7 \mathrm{~b}$ & $7.55 \pm 0.8 \mathrm{c}$ & $21.5 \pm 4.6 \mathrm{ab}$ & $0.33 \pm 0.4 \mathrm{a}$ \\
\hline 30 & $13.4 \pm 1.6 \mathrm{c}$ & $16.8 \pm 5.1 \mathrm{c}$ & $1.20 \pm 0.3 \mathrm{~b}$ & $6.0 \pm 1.7 \mathrm{c}$ & $7.11 \pm 0.8 \mathrm{c}$ & $14.1 \pm 4.1 \mathrm{c}$ & $0.28 \pm 0.4 \mathrm{a}$ \\
\hline 35 & $3.7 \pm 0.6 \mathrm{~d}$ & - & - & - & - & - & - \\
\hline
\end{tabular}

Means followed by the same letter are not significantly different; LS Means,adjusted by Tukey-Kramer.

Longevity: $\mathrm{df}=6,63 ; \mathrm{F}=23.02 ; \mathrm{P}>\mathrm{F}=0.0001$.

Fecundity: $\mathrm{df}=3,36 ; \mathrm{F}=11.30 ; \mathrm{P}>\mathrm{F}=0.0001$.

Nymphs/day: $\mathrm{df}=3,32 ; \mathrm{F}=5.02 ; \mathrm{P}>\mathrm{F}=0.0058$

Rp (Reproductive period): $\mathrm{df}=3,31 ; \mathrm{F}=9.99 ; \mathrm{P}>\mathrm{F}=0.0001$.

$\mathrm{d}$ (Pre-reproductive period): $\mathrm{df}=3,23.9 ; \mathrm{F}=51.71 ; \mathrm{P}>\mathrm{F}=0.0001$.

md (Number of progeny produced in a reproductive period equal to the pre-reproductive period): $\mathrm{df}=3,31 ; \mathrm{F}=4.78 ; \mathrm{P}>\mathrm{F}=0.0075$.

$\mathrm{rm}$ (Intrinsic rate of increase): $\mathrm{df}=3,31 ; \mathrm{F}=6.21 ; \mathrm{P}>\mathrm{F}=0.0020$

Table 3: Mean ( \pm 1 S.E.) longevity and number of offspring produced for sugarcane aphid at different temperatures $\left({ }^{0} \mathrm{C}\right)$ when reared on Columbus grass. 


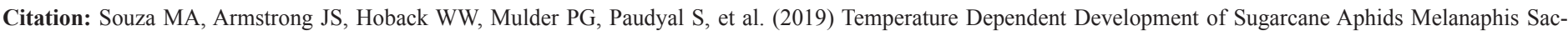

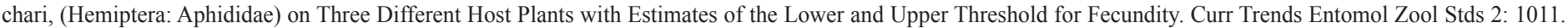
DOI:10.29011/CTEZS-1011.001011

Sugarcane aphid fecundity was higher with increases in temperatures across all hosts. The highest number of progeny produced on sorghum and Johnsongrass was observed at $25^{\circ} \mathrm{C}$, with 67.3 and 48.5 respectively, while the highest number of offspring was produced at $20{ }^{\circ} \mathrm{C}$ on Columbus grass (62.9 nymphs). At temperature ranges from $15-30{ }^{\circ} \mathrm{C}$, females produced 56.7 nymphs per female on sorghum which was significantly greater than on the other grasses, where fecundity on Johnsongrass and Columbus grass was 40.3 and 38.6 nymphs per female respectfully.

The pre-reproductive period (d) of sugarcane aphid on all grasses decreased with increasing temperature (Tables 1- 3). The reproductive period for aphids that reached maturity on the sorghum and Johnsongrasses was longest when they were at 15 ${ }^{\circ} \mathrm{C}$ while the longest reproductive period for Columbus grass was at $20{ }^{\circ} \mathrm{C}$ (Tables 1-3). The relationship between pre-reproductive period and the number of progeny produced in the same amount of time (md) varied by grass species and was longest at $15{ }^{\circ} \mathrm{C}$ for sorghum and Columbus grass (Tables 1 and 3). For Johnsongrass, md was similar for all temperatures above $10{ }^{\circ} \mathrm{C}$ (Table 2). The intrinsic rate of increase ( $\mathrm{rm}$ ) of sugarcane aphid increased on all hosts as temperature increased for both sorghum and Johnsongrass; however, on Columbus grass rm was highest at $25^{\circ} \mathrm{C}$ (Table 1-3).

Both the Weibull and Normal models used to estimate the lower and upper temperature thresholds for fecundity resulted in essentially the same temperatures, with the lower threshold estimated at $9{ }^{\circ} \mathrm{C}$, and the upper at $32{ }^{\circ} \mathrm{C}$ (Figure 1). If the peeks in the Weibull and Normal curves are used to estimate optimal fecundity, the optimal for the Weibull would be estimated to be $22.5^{\circ} \mathrm{C}$, while the optimal for the Normal would be $21.0^{\circ} \mathrm{C}$ (Figure 1). The Weibull model $(\mathrm{df}=3,67, \mathrm{MSE}=0.70, \mathrm{R}$ square $=0.82$, adj $\mathrm{R}$ square $=0.82$ ) had a slightly closer relationship with lifetime fecundity when compared to the Normal model ( $\mathrm{df}=3$, $67, \mathrm{MSE}=0.77, \mathrm{R}$ square $=0.80$, adj $\mathrm{R}$ square $=0.80)$, but both models should be adequate for determining the thresholds.

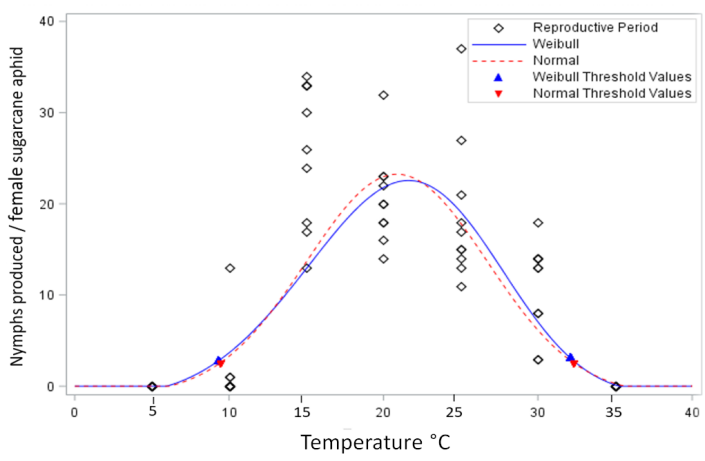

Figure 1: Lifetime fecundity fitted to the Weibull and Normal functions and used to estimate the lower and upper thresholds of fecundity for the sugarcane aphid when reared on grain sorghum at temperatures from 5 to $35{ }^{\circ} \mathrm{C}$.

\section{Discussion}

\section{Temperature and Life History}

Sugarcane aphids feed on the underside of leaves [6], potentially to avoid direct sunlight and temperatures that may exceed the upper threshold for development. In a developed sorghum canopy when water is available, temperatures can approach $7{ }^{\circ} \mathrm{C}$ lower than air temperatures [17], which are likely to affect development. This may also allow for increased survival and population growth when air temperatures are predicted to result in mortality. Based on our results, these differences are most important in sorghum and Johnson grass (Tables 1 and 2 respectively).

In our experiments, the survival and reproductive capability of sugarcane aphid was strongly affected by temperature and host. Sugarcane aphids lived longer at $5^{\circ} \mathrm{C}$ and $35^{\circ} \mathrm{C}$ when on sorghum compared to Johnsongrass or Columbus grass. Although low fecundity was observed at $10^{\circ} \mathrm{C}$, the models predicted threshold temperatures of $9{ }^{\circ} \mathrm{C}$, which is similar for other aphid species [18]. Temperatures above $30^{\circ} \mathrm{C}$ appear to impact sugarcane aphid survival and longevity. High temperatures can be lethal because of the direct effect on somatic tissue of aphids including the developing embryos and also the nutritional quality of the plant [19-22]. Columbus grass is the most tropical grass host tested and sugarcane aphid performance was poorest on this host, even at higher temperatures, suggesting the potential for secondary plant compounds or nutritional limitations. At $15^{\circ} \mathrm{C}$, sugarcane aphids reared on sorghum and Johnsongrass had the longest lifespan and reproductive period, in addition to having high fecundity. The longevity of several other aphid species has been reported to be greatest at approximately $15{ }^{\circ} \mathrm{C}[18,21,23,24]$. Above 15 ${ }^{\circ} \mathrm{C}$, sugarcane aphid longevity decreased except for those on Columbus grass, where they had the greatest longevity at $20{ }^{\circ} \mathrm{C}$. This difference was not significant and additional research on the interaction between sugarcane aphid and Columbus grass is needed to determine the reason that the relationship between temperature and longevity differed for this host.

Although an increase in temperature decreases the longevity of sugarcane aphids, this is unlikely to impact population increase because most nymphs are produced early in the adult's lifetime. Therefore, it is more advantageous for the aphid population to have a high reproductive rate at a higher temperature even when it shortens their lifespan $[21,25,26]$. Sugarcane aphids reproduced an average of 2 nymphs per female per day between 20 and $30{ }^{\circ} \mathrm{C}$. Interestingly, fewer nymphs per day were produced on Columbus grass, except at $20^{\circ} \mathrm{C}$ (Tables 1-3). This difference is also reflected in the intrinsic rate of increase which increased with increasing temperatures for sorghum and Johnsongrass, but not Columbus grass. Based on these experiments, the optimum temperature for longevity, fecundity and development of the sugarcane aphid is 


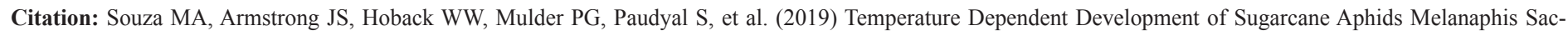

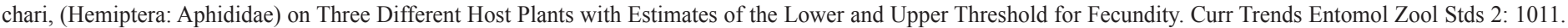
DOI:10.29011/CTEZS-1011.001011

between 21.0 and $22.5^{\circ} \mathrm{C}$. Several species of aphids have similar reproductive and survival characteristics at these temperatures [15]. When reared at a series of constant temperatures, the currantlettuce aphid, Nasonovia ribisnigri (Mosley), had a high survival rate between $16{ }^{\circ} \mathrm{C}$ and $24{ }^{\circ} \mathrm{C}$, with no mortality of nymphs occurring above $20^{\circ} \mathrm{C}$. The optimum temperature for reproduction and survival of this species was at $24{ }^{\circ} \mathrm{C}$ [26]. Wood and Starks [27] observed that for greenbug, Schizaphis graminum (Rondani), on a susceptible sorghum variety, the optimal temperature for reproduction was between $21.1{ }^{\circ} \mathrm{C}$ and $26.7{ }^{\circ} \mathrm{C}$. Walgenbach [28] observed that greenbug fecundity peaked at around $20.8^{\circ} \mathrm{C}$, whereas development rate increased until $26{ }^{\circ} \mathrm{C}$ for this species. The Asparagus aphid, Brachycorynella asparagi (Mordvilko) had its highest fecundity at $23{ }^{\circ} \mathrm{C}$ [21] and the Bird cherry-oat aphid, Rhopalosiphum padi, had the highest fecundity at $25^{\circ} \mathrm{C}[22]$.

The sugarcane aphid differs from some other recorded species of aphids by being able to survive and reproduce in a constant temperature of $30{ }^{\circ} \mathrm{C}$. Although there was a decrease in longevity and in the total number of nymphs produced, survival and fecundity were greater when compared to other species of aphids reared at $30{ }^{\circ} \mathrm{C}$ [28,21]. At $30{ }^{\circ} \mathrm{C}$, sugarcane aphids took between 5 and $6 \mathrm{~d}$ to reach the adult stage and reproduce. On sorghum and Johnsongrass, the intrinsic rate of increase was highest at $30{ }^{\circ} \mathrm{C}$ where many nymphs are produced but over a short duration. When Tables $1-3$ are observed for fecundity at $30^{\circ} \mathrm{C}$ for sorghum Johnsongrass and Columbus grass respectfully, it can be seen that the upper threshold is somewhere between $30-35^{\circ} \mathrm{C}$, and our Weibull and Normal models both predicted $32^{\circ} \mathrm{C}$ as the upper threshold, Figure 1.

From our studies, Johnsongrass is a good alternate host in the absence of sorghum even for the MLL-F lineage. Although there were fewer sugarcane aphid nymphs produced compared to sorghum, Johnsongrass should be considered a viable host. With an increase in temperature, longevity decreased but reproductive rate increased, and highest at $25^{\circ} \mathrm{C}$, the largest number of nymphs was produced (Table 2). It is expected that aphids have preferred hosts and in the absence of these hosts, they may use other less desirable plants. Starks, et al. [29] evaluated the preference of two different biotypes of greenbug (Biotype B and C) in relation to three sorghum varieties (cv OK-8, Deer and Piper) and concluded that longevity and fecundity was lower for both biotypes on nonpreferred cultivars. Columbus grass was not as productive of an alternate host as was Johnsongrass and sorghum based on lower life table statistics and the fact that no reproduction occurred at $5^{\circ} \mathrm{C}, 10^{\circ} \mathrm{C}$ and $35^{\circ} \mathrm{C}$. Temperature and quality of food influence development, survival, and reproduction of aphids [12,10,30]. Columbus grass occurs naturally in the extreme southern United States and it is likely that cooler temperatures used in these trials affected the plant quality or synthesis of photosynthate needed for sugarcane aphid nutrition. Even at $15{ }^{\circ} \mathrm{C}$, sugarcane aphids had shorter lifespans than those on sorghum or Johnsongrass. When sugarcane aphids were reared on the three hosts at $20^{\circ} \mathrm{C}$, longevity was similar to that of $15^{\circ} \mathrm{C}$, but fecundity was greater. When sugarcane aphids were reared above $20^{\circ} \mathrm{C}$, aphid longevity and fecundity decreased.

Temperature determines the physiological state of insects and consequently is the key variable that regulates survival, fecundity, and population density. Although insects are not exposed to constant temperatures in the environment, this type of study offers valuable insights into population dynamics of sugarcane aphid and strongly suggests that sugarcane aphid does not survive in northern areas of the sorghum belt even in the presence of Johnsongrass. Our results also suggest that warm temperatures in the south are likely to induce migration. Winds, especially upper air thermals, can spread aphids over long distances allowing them to reach new areas with optimal temperatures [1,31]. Information on how temperature influences the life cycle of an insect pest is essential to understanding its biology and developing IPM strategies [11,26]. In the absence of sorghum, Johnsongrass should be observed for the presence of sugarcane aphids as an indicator of dispersal to sorghum in integrated scouting programs.

\section{Acknowledgement}

We thank B. Driskel for excellent technical support and the Department of Entomology and Plant Pathology for partial funding. The use of trade, firm, or corporation names in this publication is for the information and convenience of the reader. Such use does not constitute an official endorsement or approval by the United States Department of Agriculture or the Agricultural Research Service of any product or service to the exclusion of others that may be suitable. “The United States Department of Agriculture (USDA) prohibits discrimination in all its programs and activities on the basis of race, color, national origin, age, disability, and where applicable, sex, marital status, familial status, parental status, religion, sexual orientation, genetic information, political beliefs, reprisal, or because all or part of an individual's income is derived from any public assistance program.

\section{References}

1. Knutson A, Bowling R, Brewer M, Bynum E, Porter P (2016) The Sugarcane Aphid: Management Guidelines for Grain and Forage Sorghum in Texas. Texas AgriLife Extension and Research.

2. Nibouche S, Costet L, Holt JR, Jacobson A, Pekarcik A, et al. (2018) Invasion of sorghum in the Americas by a new sugarcane aphid (Melanaphis sacchari) superclone. PLoS ONE 13: e0196124.

3. Armstrong JS, Rooney WL, Peterson GC, Villanueva RT, Brewer MJ, et al. (2015) Sugarcane aphid Melanaphis sacchari, (Hemiptera: Aphididae): Host range and sorghum resistance including cross-resistance from greenbug sources. J Econ Entomol 108: 576-582. 
Citation: Souza MA, Armstrong JS, Hoback WW, Mulder PG, Paudyal S, et al. (2019) Temperature Dependent Development of Sugarcane Aphids Melanaphis Sacchari, (Hemiptera: Aphididae) on Three Different Host Plants with Estimates of the Lower and Upper Threshold for Fecundity. Curr Trends Entomol Zool Stds 2: 1011. DOI:10.29011/CTEZS-1011.001011

4. Nibouche S, Mississipi S, Fartek B, Delatte H, Reynaud B, et al. (2015) Host Plant Specialization in the Sugarcane Aphid Melanaphis sacchari. PLoS ONE 10: e0143704.

5. $\quad$ Armstrong JS, Harris-Shultz K, Ni X, Wang H, Knoll JE, et al. (2019) Utilizing Biodemographic Indices to Identify Perennial Bioenergy Grasses as Sugarcane Aphid (Hemiptera: Aphididae) Host Plants. Trends In Entomol 19: 1-14.

6. Bowling RD, Brewer MJ, Kerns DL, Gordy J, Seiter N, et al. (2016) Sugarcane aphid (Hemiptera: Aphididae): a new pest on sorghum in North America. J Integr Pest Manag 7: 1-13.

7. Van Rensburg NJ (1973) Notes on the occurrence and biology of the sorghum aphid in South Africa. J Entomol Soc S Afr 36: 293-298.

8. Sharma HC, Sharma SP, Munghate RS (2013) Phenotyping for resistance to the sugarcane aphid Melanaphis sacchari (Hemiptera: Aphididae) in Sorghum bicolor (Poaceae). Int J Trop Insect Sci 33: 227-238.

9. Zapata S, Dudensing R, Sekula D, Esparza-Díaz G, Villanueva R (2018) Economic impact of the sugarcane aphid outbreak in South Texas. J Agr Appl Econ 50: 104-128.

10. Aalbersberg YK, Westhuisen MC vander, Hewitt PH (1987) Development rate, fecundity and life span of apterae of the Russian wheat aphid, Diuraphis noxia (Mordvilko) (Hemiptera: Aphididae) under controlled conditions. B Entomol Res 77: 629-635.

11. Özder N, Sağlam Ö (2013) The effects of temperature for development time, fecundity and reproduction on some ornamental aphid species. J Cent Eur Agric 14: 149-157.

12. Campbell A, Frazer BD, Gilbert N, Gutierrez AP, Mackauer M (1974) Temperature requirements of some aphids and their parasites. J Appl Ecol 11: 431-438.

13. Wyatt IJ, White PF (1977) Simple estimation of intrinsic increase rates for aphid and tetranychid mites. J Appl Ecol 14: 757-766.

14. SAS Institute (2010) SAS users guide, version 9.3. SAS Institute, Cary, NC.

15. Merrill SC, Holtzer TO, Peairs FB (2009) Diuraphis noxia reproduction and development with a comparison of intrinsic rates of increase to other important small grain aphids: A Meta-Analysis. Environ Entomol 38: 1061-1068.

16. Burnham KP, Anderson DR (2002) Model selection and multimodel inferences: the practical information theoretic approach. Springer, New York.

17. Olufayo, Baldy C, Ruelle P (1996) Sorghum yield, water use and canopy temperatures under Water Manage 30: 77-90. different levels of irrigation. Agric

18. Conti BF, Bueno VH, Sampaio MV, Sidney LA (2010) Reproduction and fertility life table of three aphid species (Macrosiphini) at different temperatures. Rev Bras Entomol 54: 654-660.
19. Daniels NE (1967) The effects of high temperatures on greenbug, Schizaphis graminum, reproduction. J Kans Ent Soc 40: 133137.

20. Campbell A, Mackauer M (1977) Reproduction and population growth of the pea aphid (Homoptera: Aphididae) under laboratory and field conditions. Can Entomol 109: 277-284.

21. Hayakawa DL, Grafius E, Stehr FW (1990) Effects of temperature on longevity, reproduction, and development of the asparagus aphid (Homoptera: Aphididae) and the parasitoid, Diaeretiella rapae (Hymenoptera: Braconidae). Environ Entomol 19: 890-897.

22. Asin L, Pons $X$ (2001) Effect of high temperature on the growth and reproduction of corn aphids (Homoptera: Aphididae) and implications for their population dynamics on the Northeastern Iberian Peninsula. Environ Entomol 30: 1127-1134.

23. Kieckhefer RW, Elliott NC (1989) Effect of fluctuating temperatures on the development of immature Russian wheat aphid (Homoptera: Aphididae) and demographic statistics. J Econ Entomol 82: 119-122.

24. Michels GJ, Behle RW (1989) Influence of temperature on reproduction development, and intrinsic rate of increase of Russian wheat aphid greenbug and bird cherry-oat aphid (Homoptera: Aphididae). J Econ Entomol 82: 439-444.

25. Girma M, Wilde G, Reese JC (1990) Influence of temperature and plant growth stage on development, reproduction, life span, and intrinsic rate of increase of the Russian wheat aphid (Homoptera: Aphididae). Environ Entomol 19: 1438-1442.

26. Diaz BM, Fereres A (2005) Life table and population parameters of Nasanovia ribisnigri (Homoptera: Aphididae) at different constant temperatures. Environ Entomol 34: 527-534.

27. Wood EA Jr, Starks KJ (1972) Effect of temperature and host plant interaction on the biology of three biotypes of the greenbug. Environ Entomol 1: 230-234.

28. Walgenbach DD, Elliott NC, Kieckhefer RW (1988) Constant and fluctuating temperature effects on developmental rates and life table statistics of the greenbug (Homoptera: Aphididae). J Econ Entomol 81: 501-507.

29. Starks KJ, Wood EA, Teetes GL (1973) Effects of temperature on the preference of two greenbug biotypes for sorghum selections. Environ Entomol 2: 351-354.

30. Singh K, Singh R (2015) Effect of Temperature on the Life History Traits of Aphis gossypii Glover (Homoptera: Aphididae) on Bottle Gourd, Laginaria Siceraria (Molina) Standl. (Cucurbitaceae). Int J Life Sci Pharma Res 4: 179-183.

31. Lowe AD (1966) Some effects of weather on aphids in crops and pastures in Canterbury, New Zealand. Proc NZ Ecol Soc 13: 86-90. 